\title{
An unusual presentation of colon perforation following percutaneous nephrolithotomy
}

\author{
Barbara Chubak, MD; Joshua M. Stern, MD
}

Albert Einstein College of Medicine/Montefiore Medical Center, Bronx, NY

Cite as: Can Urol Assoc J 2014;8(11-12):e862-6. http://dx.doi.org/10.5489/cuaj.2154 Published online November 24, 2014.

\section{Abstract}

Colon perforation is a rare but serious complication of percutaneous nephrolithotomy (PCNL), meriting particular attention to its signs and symptoms for prompt diagnosis and treatment. We report an unusual presentation of colon perforation following tubeless PCNL, characterized by sore throat, pneumomediastinum, and neck and shoulder crepitus. In addition to the details of this case, we review the current literature on bowel injury during PCNL and its management.

\section{Introduction}

Percutaneous nephrolithotomy (PCNL) is the gold standard for the elimination of large renal calculi, ${ }^{1,2}$ providing maximal stone-free rates with minimal trauma to the kidney and surrounding tissues. Nonetheless, significant risks remain, including those of bowel perforation, pleural injury, and bleeding. Though injury to the retroperitoneal colon is rare, occurring in fewer than $1 \%$ of cases, ${ }^{3,4}$ the potential severity of this complication is such that a high index of suspicion and alertness for its signs and symptoms are essential during the postoperative period. In this paper, we describe an unusual presentation of colon perforation following PCNL and discuss its management, with reference to the relevant literature.

\section{Case report}

An obese 78-year-old female with no surgical history presented to the emergency department with left-sided flank and abdominal pain. Supine computed tomography (CT) scan of the abdomen and pelvis revealed complete duplication of the renal collecting system bilaterally, with hydronephrosis of the left upper-pole moiety secondary to 3 large obstructing calculi at the ureteropelvic junction. The patient was referred to urology. As her symptoms were well-controlled by medication alone, a plan was made to defer any urologic instrumentation until 3 weeks after another elective surgical procedure, laparoscopic cholecystectomy for biliary colic, following which she would undergo PCNL.

After the patient was administered cefazolin for antibiotic prophylaxis, a PCNL was performed with the patient in a prone position. Percutaneous access to a posterior middle calyx, corresponding to the lower part of the upper-pole moiety, was obtained by an experienced interventional radiologist under fluoroscopic vision. The puncture was made subcostally, just lateral to the paraspinal muscles (Fig. 1). Using a balloon dilator, the percutaneous tract was upsized to $30-\mathrm{Fr}$ in routine fashion, without any suspicion of bowel injury. The stones were removed intact, a JJ ureteral stent was placed antegrade, and after hemostatic matrix was placed into the tract, the percutaneous nephrostomy tube was removed. No feces were seen on the balloon or the 30-Fr access sheath. Postoperative labs were unremarkable, with a white-blood-cell count (WBC) of 4 , unchanged from her preoperative baseline count.

Postoperatively, the patient was febrile to $101.2^{\circ} \mathrm{F}$, but she subsequently defervesced and remained afebrile with stable vital signs throughout the rest of her hospital stay. Blood tests were similarly reassuring, with her WBC reaching a zenith of 8.9 on the morning of postoperative day (POD) 1 and subsequently trending downward. Cefazolin was continued for perioperative prophylaxis through POD 1, as per routine. The morning after surgery, the patient denied abdominal complaints, but reported a sore throat and substernal chest pain; palpation did not reproduce this pain, but did elicit crepitus at the neck. A plain film of the chest demonstrated pneumomediastinum, pneumoperitoneum, and air within the soft tissues of the neck (Fig. 2). 


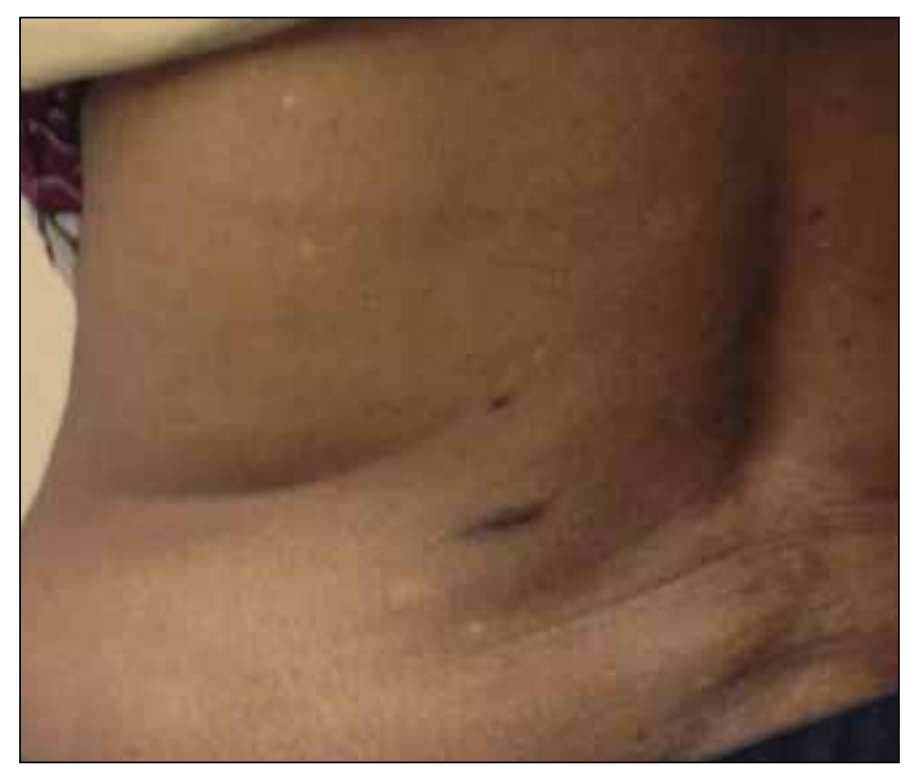

Fig. 1. Location of percutaneous access.

On POD 2, the patient remained stable and reported improvement of her chest pain, complaining only of soreness at her throat and left flank. Nonetheless, a CT scan of the thorax, abdomen, and pelvis was performed with oral contrast, which showed air within the mediastinum, retroperitoneum, and peritoneal cavity, with a focal collection of contrast adjacent to the descending colon (Fig. 3). The general surgery service was consulted, and the patient was taken to the operating room for diagnostic laparoscopy. Mobilization of the descending colon revealed a single $1-\mathrm{cm}$ defect within its posterior wall, with an adjacent collection of pus and feces. The defect was closed primarily and the transverse colon brought to the skin in a diverting loop colostomy.

The patient's course following this surgery was unremarkable, and she was discharged 3 days later, 5 days after her PCNL. The JJ ureteral stent was removed 3 weeks later. She returned to the operating room 2 months after the creation of the loop colostomy for its reversal. This final operation was well-tolerated, and the patient returned to her baseline health.

\section{Discussion}

Because colon perforation is a rare complication of PCNL, the published literature about it is largely limited to case reports (Table 1). Two possible patterns are described: injuries that are identified radiographically immediately in or after surgery ${ }^{5-7}$ and injuries that are identified in a delayed fashion due to signs of fecaluria and leukocytosis. ${ }^{8,9}$ Our case describes an alternative delayed presentation, with symptoms of throat and chest pain, and signs of neck and shoulder crepitus with pneumomediastinum. This is the first such presentation in the literature.

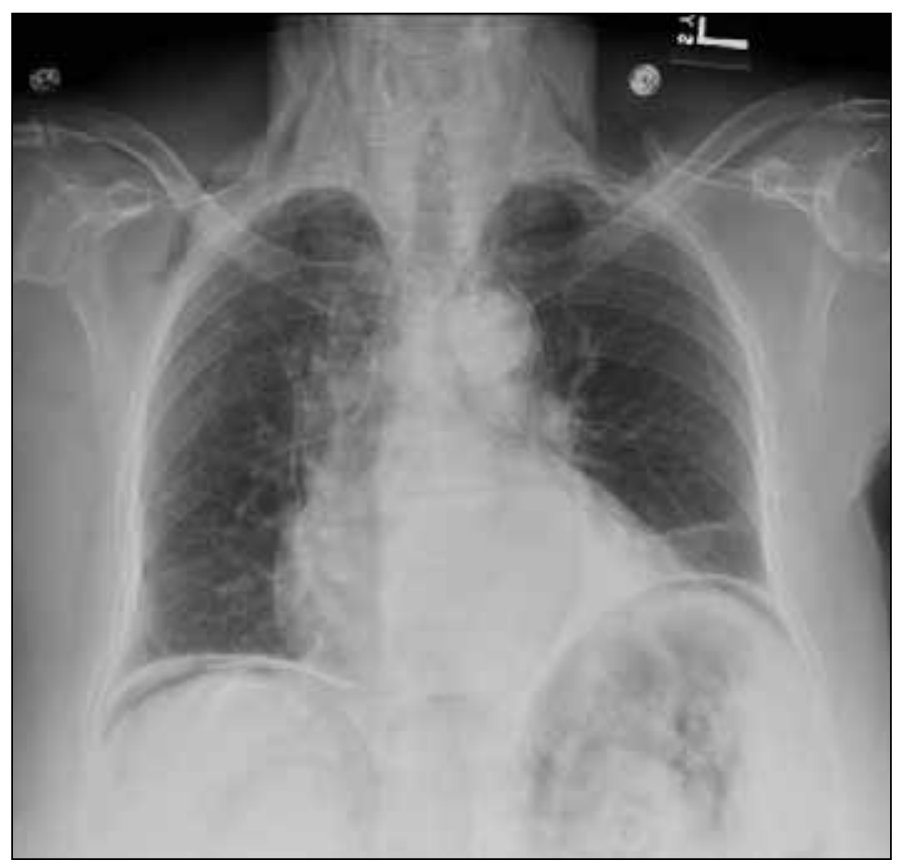

Fig. 2. Chest x-Ray, postoperative day 1.

Upper-body findings are not immediately suggestive of subdiaphragmatic pathology, and care was taken to rule out an intrathoracic injury, specifically a tracheal tear from intubation. CT scan of the chest included esophageal contrast to assess for any extravasation and bronchoscopy performed on her return to the operating room was normal. It was tempting to attribute the pneumoperitoneum seen on her chest radiography to residual insufflation from the laparoscopic cholecystectomy 3 weeks prior. Pneumoperitoneum following this surgery seldom persists more than 1 to 2 weeks; ${ }^{10}$ however, several cases have been reported in the gastroenterologic literature of colonoscopic bowel perforations associated with neck pain, subcutaneous emphysema, and radiographic findings of pneumomediastinum with pneumoperitoneum and pneumoretroperitoneum. ${ }^{11-14}$

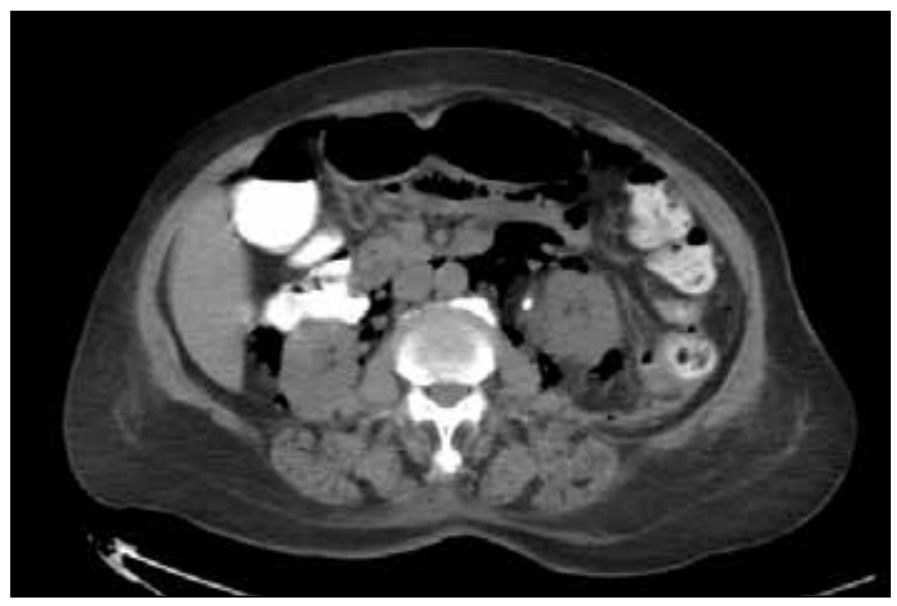

Fig. 3. Computed tomography scan demonstrating colon perforation. 


\section{Table 1. Summary of case reports of bowel injury from PCNL}

Case Location of injury

Goger E, et al. (2012)

Kachrilas S, et al. $(2012)^{16}$

Juan YS, et al. (2006)

Al-Assiri M, et al. $(2005)^{6}$

Noor Buchholz NP $(2004)^{8}$

Begliomini $\mathrm{H}$, Mattos Jr. D. (2002) ${ }^{17}$

Goswami AK, et al. $(2001)^{5}$

Gerspach JM, et al. $(1997)^{18}$

Appel R, et al. (1988)
Neustein P, et al.
$(1986)^{20}$
Culkin DJ, et al.
$(1985)^{21}$
Vallancien G, et al.
$(1985)^{3}$

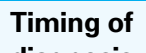
diagnosis

$$
\begin{gathered}
\text { Descending } \\
\text { colon } \\
\text { Descending } \\
\text { colon } \\
\text { Duodenum } \\
\text { Descending } \\
\text { colon }
\end{gathered}
$$

\section{Descending} colon

Intraoperative

POD 3

POD 1

Intraoperative

POD 2

POD 3

POD 4 colon

Jejunum

Intraoperative access, posterior axillary access

Female, lower pole access

Left PCNL, posterior axillary access

Left PCNL, horseshoe kidney

Female, left PCNL, lower pole access

Left PCNL postoperative"

POD 0

POD 2

Lower pole access

Left PCNL, lower pole access

None

Female, left PCNL

Left PCNL

Female, lower pole access

Left PCNL, lower pole access

Left PCNL, lower pole access
POD 1
Symptoms/signs

None (attempted

pyelogram showed contrast in bowel)

Feculent nephrostomy drainage, fever

Feculent nephrostomy drainage, fever

None

Fever, abdominal pain

Fever, abdominal pain, nausea/vomiting

Flank pain, purulent discharge around PCN, poor urine output from PCN

None (attempted pyelogram showed contrast in bowel)

Flank pain, feculent nephrostomy drainage, leukocytosis

Abdominal pain

None (incidental finding on imaging to assess residual stone burden)

Fever, feculent nephrostomy drainage, abdominal pain

\section{Fever}

\section{Fever}

Feculent nephrostomy drainage

None (attempted nephroscopy visualized colon lumen)

None (incidental finding on imaging)

\section{Abdominal pain}

Lack of nephrostomy drainage

Shock, rectal hemorrhage

Abdominal pain, fever, gas from nephrostomy tract

\section{Management}

Non-operative (PCN tube withdrawn into bowel)

Non-operative**

Non-operative ${ }^{* *}$

Non-operative ${ }^{* *}$

Non-operative ${ }^{* *}$

Non-operative ${ }^{* *}$

Non-operative ${ }^{* *}$

Non-operative (catheter drainage of bowel, ureteral stent)

Operative (bowel resection, ureteral stent)

Operative (primary repair of bowel perforation)

\section{Non-operative ${ }^{* *}$}

Non-operative (PCN removed, pericolonic drain, ureteral stent) Non-operative (PCN removed, pericolonic drain, nasogastric drain)

Non-operative (PCN removed, ureteral stent)

Non-operative (PCN removed)

Non-operative (catheter drainage of bowel, pericolonic drain, ureteral stent)

Non-operative (ureteral stent, bowel rest)

Non-operative ${ }^{* *}$

Non-operative (PCN drainage, nasogastric drainage)

Operative (bowel resection $\mathrm{w} /$ transverse colostomy and heminephrectomy)

Operative (primary repair of bowel perforation) 
Established risk factors for colon injury during PCNL include slim body habitus, female sex, prior colon surgery, access to the left kidney at the posterior axillary line and lower pole, and most of all a retrorenal loop of colon. ${ }^{4-9,15}$ Other than her sex (which may not be as strong a risk factor as has been suggested, given the preponderance of male patients in the existing case reports, Table $1^{3,5-9,16-21}$ ) and the side of her surgery, our patient had none of these risk factors, with no evidence of retrorenal colon on her preoperative CT scan. While anatomic anomalies, such as horseshoe kidney, are associated with an increased rate of retrorenal colon, ${ }^{5,22}$ duplication of the collecting system typically does not displace the kidney from its standard anatomic location and is unlikely to be a relevant risk factor.

Comparative reviews of CT scans obtained in the supine and prone positions suggest that for a given patient, the colon is more than twice as likely to be retrorenal in the prone position, with CT scan in the supine position inadequately representing this challenging anatomy. ${ }^{23,24}$ Our patient's CT was obtained in the emergency department without any surgery specifically in mind, and given the rarity of this complication, re-imaging while prone seems excessive for the routine evaluation of a patient for PCNL. Studies of the relative safety of supine versus prone positioning have not demonstrated any difference in the risk of bowel perforation or other major complications. ${ }^{25,26}$

Recent reports describing bowel perforation during PCNL have emphasized the opportunity for non-operative management for the injury, with placement of the percutaneous nephrostomy tube into the bowel lumen to act as a drain..$^{5-7,9,27}$ This opportunity is predicated on the presence of an indwelling nephrostomy tube to leave as an enteric drain. Our tubeless surgery precluded this possibility. Had a tube been left in place, the nature of the patient's injury, which was not through-and-through but skived the bowel to leave only a single defect, did not lend itself to ready intubation of the bowel lumen. Thus, the possibility of better managing a potential bowel injury is not a compelling argument against tubeless PCNL, which studies have shown to be no less safe than the standard procedure..$^{28,29}$

\section{Conclusion}

Contrary to the enthusiasm for conservative management of surgical complications, such as bowel perforation following PCNL, this case is a reminder that there are circumstances in which reoperation remains the most appropriate course. ${ }^{27,30}$ Our patient's benign clinical appearance, with a chief complaint of sore throat and without fever, leukocytosis, leukopenia, abdominal pain, or other clinical evidence of peritonitis, belied the peritoneal involvement seen on imaging and the bowel wall defect with fecal spillage seen laparoscopically. With recognition of the injury, despite its unusual presentation, and prompt operative management, the patient achieved a relatively rapid and uncomplicated recovery.

Competing interests: Dr. Chubak and Dr. Stern declare no competing financial or personal interests.

This paper has been peer-reviewed.

\section{References}

1. Skolarikos A, Alivizatos $G$, de la Rosette JJ. Percutaneous nephrolithotomy and its legacy. Eur Urol 2005;47:22-8. http://dx.doi.org/10.1016/j.eururo.2004.08.009

2. Preminger GM, Assimos DG, Lingeman JE, et al. Chapter 1: AUA Guideline on management of staghorn calculi: Diagnosis and treatment recommendations. J Urol 2005;173:1991-2000. http://dx.doi. org/10.1097/01.ju.0000161171.67806.2a

3. Vallancien G, Capdeville R, Veillon B, et al. Colonic perforation during percutaneous nephrolithotomy. J Urol 1985;134:1185-7.

4. de la Rosette JJ, Assimos D, Desai M, et al. The Clinical Research Office of the Endourological Society Percutaneous Nephrolithotomy Global Study: Indications, complications, and outcomes in 5803 patients. J Endourol 2011;25:11-7. http://dx.doi.org/10.1089/end.2010.0424

5. Goswami AK, Shrivastava $P$, Mukherjee A, et al. Management of colonic perforation during percutaneous nepholithotomy in horseshoe kidney. J Endourol 2001;15:989-91. http://dx.doi. org/10.1089/089277901317203065

6. Al-Assiri $M$, Binsaleh S, Libman J, et al. Jejunal perforation during percutaneous nephrolithotripsy. Scientific World Journal 2005;5:496-9. http://dx.doi.org/10.1100/tsw.2005.67

7. Goger E, Guven $S$, Gurbuz R, et al. Management of a colon perforation during pediatric percutaneous nephrolithotomy. J Endourol 2012;26:1118-20. http://dx.doi.org/10.1089/end.2011.0433

8. Noor Buchholz NP. Colon perforation after percutaneous nephrolithotomy revisited. Urol Int 2004;72:8890. http://dx.doi.org/10.1159/000075282

9. Juan YS, Huang $\mathrm{CH}$, Chuang SM, et al. Colon perforation: A rare complication during percutaneous nephrolithotomy. Kaohsiung J Med Sci 2006;22:99-101. http://dx.doi.org/10.1016/S1607$551 \times(09) 70228-1$

10. Millitz K, Moote DJ, Sparrow RK, et al. Pneumoperitoneum after laparoscopic cholecystectomy: Frequency and duration as seen on upright chest radiographs. AJR Am J Roentgenol 1994;163:837-9. http:// dx.doi.org/10.2214/air.163.4.8092019

11. Bakker J, van Kersen F, Bellaar Spruyt J. Pericardium and pneumomediastinum after polypectomy. Endoscopy 1991;23:46-7. http://dx.doi.org/10.1055/s-2007-1010607

12. Park NS, Choi JH, Lee DH, et al. Pneumoperitoneum, pneumomediastinum, pneumopericardium, and subcutaneous emphysema after colonoscopic examination. Gut Liver 2007;1:79-81. http://dx.doi. org/10.5009/gnl.2007.1.1.79

13. Newstead B, Smith JE. A pain in the neck. J R Army Med Corps 2010;156:100-1. http://dx.doi. org/10.1136/iramc-156-02-07

14. Murariu D, Tatsuno BK, Tom MK, et al. Subcutaneous emphysema, pneumopericardium, pneumomediastinum and pneumoretroperitoneum secondary to sigmoid perforation: A case report. Hawaii J Med Public Health 2012;71:74-7.

15. Atar $M$, Hatipoglu NK, Soylemez H, et al. Relationship between colon and kidney: A critical point for percutaneous procedures. Scand J Urol 2013;47:122-5. http://dx.doi.org/10.3109/00365599.2 012.707685

16. Kachrilas S, Papatsoris A, Bach C, et al. Colon perforation during percutaneous renal surgery: A 10-year experience in a single endourology centre. Urol Res 2012;40:263-8. http://dx.doi.org/10.1007/ s00240-012-0475-1

17. Begliomini H, Mattos Jr D. Bowel perforation during percutaneous renal surgery. Int Braz I Urol 2002;28:533-6.

18. Gerspach JM, Bellman GC, Stoller ML, et al. Conservative management of colon injury following percutaneous renal surgery. Urology 1997;49:831-6. http://dx.doi.org/10.1016/S0090-4295(97)00237-9

19. Appel R, Musmanno MC, Knight JG. Nephrocolic fistula complicating percutaneous nephrostomy. I Urol 1988; 140:1007-8

20. Neustein P, Barbaric ZL, Kaufmann JJ. Nephrocolic fistula: A complication of percutaneous nephrostolithotomy. J Urol 1986;135:571-3. 
Chubak and Stern

21. Culkin DJ, Wheeler JS JI, Canning JR. Nephro-duodenal fistula: A complication of percutaneous nephrolithotomy. J Urol 1985;134:528-30.

22. El-Nahas AR, Shokeir AA, E-Assmy AM, et al. Colonic perforation during percutaneous nephrolithotomy: study of risk factors. Urology 2006;67:937-41. http://dx.doi.org/10.1016/j.urology.2005.11.025

23. Tuttle DN, Yeh BM, Meng MV, et al. Risk of injury to adjacent organs with lower-pole fluoroscopically guided percutaneous nephrostomy: Evaluation with prone, supine, and multiplanar reformatted CT. J Vasc Interv Radiol 2005;16:1489-92. http://dx.doi.org/10.1097/01. RVI.0000175331.93499.44

24. Chalasani V, Bissoon D, Bhuvanagir AK, et al. Should PCNL patients have a CT in the prone position preoperatively? Can J Urol 2010;17:5082-6.

25. Baard J, Kamphuis GM, Westendarp M, et al. How well-tolerated is supine percutaneous nephrolithotomy? Curr Opin Urol 2014;24:184-8. http://dx.doi.org/10.1097/MOU.0000000000000023

26. Valdivia JG, Scarpa RM, Duvdevani $M$, et al. Supine versus prone position during percutaneous nephrolithotomy: A report from the clinical research office of the Endourological Society Percutaneous Nephrolithotomy Global Study. J Endourol 2011;25:1619-25. http://dx.doi.org/10.1089/end.2011.0110
27. Traxer 0 . Management of iniury to the bowel during percutaneous stone removal. J Endourol 2009;23:1777-80. http://dx.doi.org/10.1089/end.2009.1553

28. Amer T, Ahmed K, Bultitude M, et al. Standard versus tubeless percutaneous nephrolithotomy: A systematic review. Urol Int 2012;88:373-82. http://dx.doi.org/10.1159/000336145

29. Korkes F, Lopes Neto AC, Lucio J 2nd, et al. Management of colon injury after percutaneous renal surgery. J Endourol 2009;23:569-73. http://dx.doi.org/10.1089/end.2008.0506

30. Bezerra CA, Korkes F, Neto ACL, et al. Management of colon injury after percutaneous renal surgery. J Endourol 2009;23:569-73. http://dx.doi.org/10.1089/end.2008.0506

Correspondence: Dr. Barbara Chubak, Montefiore Medical Center, 111 East 210th Street, Bronx, NY 10467; bchubak@montefiore.org 